\title{
A dynamic aerosol module for global chemical transport models: Model description
}

\author{
Michael Herzog \\ Department of Atmospheric, Oceanic, and Space Sciences, University of Michigan, Ann Arbor, Michigan, USA
}

Debra K. Weisenstein

Atmospheric and Environmental Research, Inc., Lexington, Massachusetts, USA

Joyce E. Penner

Department of Atmospheric, Oceanic, and Space Sciences, University of Michigan, Ann Arbor, Michigan, USA

Received 1 December 2003; revised 28 June 2004; accepted 30 June 2004; published 17 September 2004.

[1] We have developed a dynamic aerosol model that is capable of treating the binary nucleation of sulfate gas and its condensation to form aerosol particles. Coagulation among sulfate particles and of sulfate particles with nonsulfate particles is also treated. The model is built in a modular fashion that allows its easy incorporation into a global chemical transport model. The model uses the method of modes and moments to describe the aerosol size distribution, with an arbitrary number of modes possible. The parameterizations in the model are valid for tropospheric as well as stratospheric conditions. No operator splitting or fixed time steps are applied so that all aerosol processes are allowed to fully interact with each other during each time step. Here we examine the predictions of the model in comparison to a sectional model for a suite of test cases chosen to represent the range of possibilities in a global CTM. We show that the predictions for both number and surface area are within a factor of 1.2 of the sectional model for the four mode version of the model and are only slightly degraded if only two modes are specified. The prediction of the number of accumulation mode particles is within a factor of 2.1 of that from the sectional model within the boundary layer. INDEX TERMS: 0305 Atmospheric Composition and Structure: Aerosols and particles (0345, 4801); 0345

Atmospheric Composition and Structure: Pollution—urban and regional (0305); 0365 Atmospheric Composition and Structure: Troposphere - composition and chemistry; 0320 Atmospheric Composition and Structure: Cloud physics and chemistry; 1610 Global Change: Atmosphere (0315, 0325); KEYWORDS: aerosol dynamics, aerosol size distribution, aerosol number concentration

Citation: Herzog, M., D. K. Weisenstein, and J. E. Penner (2004), A dynamic aerosol module for global chemical transport models: Model description, J. Geophys. Res., 109, D18202, doi:10.1029/2003JD004405.

\section{Introduction}

[2] There has been increased recognition of the importance of aerosols to climate, and a corresponding interest in including the indirect and direct effects of particles in models for climate and climate change prediction. Sulfate compounds have been of particular interest for a number of reasons: they often constitute a major fraction of the mass of particulate matter (e.g., in the eastern United States [see, e.g., Malm et al., 1994]); sulfur has both natural and anthropogenic sources; and new particle formation from gas phase sulfate is important in determining aerosol number concentrations, which are needed to compute indirect effects [Penner et al., 2001]. However, the presence of nonsulfate aerosol particles can significantly alter new particle formation from gas phase sulfate if gaseous sulfate

Copyright 2004 by the American Geophysical Union. 0148-0227/04/2003JD004405 can condense onto preexisting aerosol particles and draw down the sulfate concentration below the level needed for homogeneous nucleation. Commonly considered nonsulfate aerosol types in global Chemistry and Transport Models (CTMs) are sea salt, mineral dust, soot and other organic compounds. Measurements have shown the importance of nonsulfate aerosols in a variety of environments [e.g., Bates et al., 1998; Russell et al., 1999; Raes et al., 2000; Huebert et al., 2003].

[3] In the past many CTMs assumed fixed size distributions when evaluating the radiative effects of aerosols [Penner et al., 2001, 2002]. However, aerosol number concentrations should respond to variations in sources and sinks of particles and account for the observed significant temporal and spatial variability in aerosol size distributions [Clarke and Kapustin, 2001].

[4] Several approaches have been developed to represent the aerosol size distribution in atmospheric models, including continuous [e.g., Suck and Brock, 1979; Tsang and 
Brock, 1983], discrete (with many variants, including sectional) [e.g., Gelbard and Seinfeld, 1980], moment [Wright et al., 2001], and modal representations [e.g., Whitby et al., 1991].

[5] Recently, aerosol size distribution were predicted within the framework of several regional and global models. For example, $Y u$ et al. [2003] (six-moment approach), Wilson et al. [2001] (modal approach), Binkowski and Roselle [2003] and Mebust et al. [2003] (modal approach), Ghan et al. [2001] (modal approach), Jacobson [2001] (moving center sectional approach), and $Y$. Zhang et al. [2004] (sectional approach) simulated aerosol size distributions with a main focus on tropospheric aerosols. Weisenstein et al. [1997] and Timmreck [2001] applied a sectional approach to simulate stratospheric sulfate aerosol in two-dimensional and threedimensional global models, respectively.

[6] Here we present a fast aerosol module for a global CTM that is based on a modal approach and predicts the formation of sulfate aerosol, its size distribution and the interaction between sulfate and nonsulfate aerosol components. The nonsulfate aerosol components that we consider are assumed to follow a fixed size distribution. The simulations that we present here were done off-line from the CTM, so that there is no influence from transport in these simulations.

[7] Previous work by Wilson et al. [2001] which is conceptually similar to our dynamic aerosol model uses a simplified homogeneous nucleation scheme and an operator splitting method to achieve a one hour time step. However, during nucleation events coagulation and condensation are as important as nucleation itself. An accurate treatment of those events is only possible if all relevant processes are allowed to interact on the short timescales typical for nucleation. Nucleation largely determines the aerosol number concentration and size in the free troposphere and lower stratosphere. Thus the chosen nucleation scheme has a strong impact on the aerosol number concentration [Korhonen et al., 2003]. In our model, no operator splitting or fixed time steps are applied to processes associated with the aerosols, so that all processes are allowed to fully interact with each other during each time step. The time step is dynamically adjusted in order to achieve a predefined accuracy of the numerical scheme. The model is formulated for an arbitrary number of modes. The code has a modular structure so that it is easy to exchange and test different parameterizations and to add or remove different processes. In the current version we implemented four different nucleation schemes.

[8] In addition, our formulations are valid for a wide range of atmospheric conditions that cover tropospheric as well as stratospheric conditions. The vapor pressure over the sulfuric acid solution is also predicted. This is important for an accurate prediction of the sulfate molecules in the gas phase in a global CTM since the vapor pressure over the solution varies over many orders of magnitude from the lower troposphere to the stratosphere.

[9] We use a sectional model as a benchmark to validate our model [Weisenstein et al., 1997]. The sectional model can represent any form of the size distribution and accurately predict its evolution. However, the sectional model only treats pure sulfate aerosol particles and is computationally expensive. We compare the differences between the new aerosol module and the sectional model to quantify the errors in the new aerosol module. Then, we compare the differences between the aerosol module with and without nonsulfate aerosols to examine the effect of nonsulfate aerosol particles on number concentrations and the aerosol size distribution.

\section{Model Description}

[10] The UMaer model describes the dynamics of sulfate aerosol and its interaction with primary emitted nonsulfate aerosol components based on the method of modes and moments. The term mode refers to an aerosol subpopulation characterized by an analytical function for its size distribution. In our model we assume that each mode follows a lognormal distribution. By using more than one mode we treat the size distribution of the total aerosol population as a superposition of lognormal distributions. Using proper definitions for each mode the modes can be identified with the nucleation, accumulation or coarse mode. We also use separate modes to distinguish between aerosol subpopulations of different composition.

[11] In the current implementation of UMaer we use two or more modes for sulfate aerosol. The exact number of sulfate and nonsulfate aerosol modes are input parameters to the code which are provided during an initialization step. Here we present results from simulations with two and four sulfate aerosol modes. If nonsulfate aerosol components are included, we use two modes to represent organic and black carbon, and four additional modes to represent mineral dust and sea salt particles in the submicron and supermicron range.

[12] Since a lognormal distribution is defined by three parameters (total number concentration, geometric mean radius and geometric standard deviation) each mode is uniquely described by three moments. The radial moments of a size distribution are defined by

$$
\mu_{k}=\int_{0}^{\infty} r^{k} \frac{d N(r)}{d r} d r
$$

where $d N(r) / d r$ is the number of particles in the interval between $r$ and $r+d r$. The lowest four moments are related to the total number concentration $\left(\mu_{0}\right)$, the mean radius $\left(\mu_{1}\right)$, the surface concentration $\left(\mu_{2}\right)$, and the aerosol mass concentration $\left(\mu_{3}\right)$. If the size distribution is lognormal the moments can be calculated analytically [Seinfeld and Pandis, 1997].

[13] In the current implementation we predict two moments for the sulfate aerosol number and mass concentration. The geometric standard deviation of each mode is assumed to be constant during the time integration. Nonsulfate aerosol modes are assumed to follow a predefined background size distribution that does not change during the time integration. However, nonsulfate aerosol becomes mixed with sulfate when sulfuric acid condenses onto these aerosols, when pure sulfate aerosols coagulate with the nonsulfate aerosol, or when sulfate is formed through aqueous reactions in drops that contain nonsulfate aerosols, so that the amount of sulfate associated with each nonsulfate aerosol mode must also be predicted in the model. Humidity 
growth of sea salt and organic particles and the particle growth due to sulfate associated with all particle types is included.

\subsection{Sulfate Aerosol Dynamics}

\subsubsection{Homogeneous Nucleation}

[14] Homogeneous nucleation is the process whereby new particles are formed from the gas phase. Here we consider binary homogeneous nucleation in the sulfuric acid, water system.

[15] In many regions the aerosol number concentration is dominated by the number of sulfate aerosol particles that are formed by homogeneous nucleation. Thus homogeneous nucleation is one of the main drivers for the total aerosol number concentration. Several parameterizations exist for binary nucleation of sulfate aerosol. However, the predictions from these parameterizations can differ substantially [e.g., Zhang et al., 1999].

[16] We implemented four different nucleation parameterizations in our aerosol module [Zhao and Turco, 1995; Fitzgerald and Hoppel, 1998; Kulmala et al., 1998; Vehkamäki et al., 2002]. All schemes are based on the classical theory that treats sulfate aerosol particles as liquid droplets. Hydration effects are included in the Kulmala and Vehkamaeki schemes.

[17] Here we focus on results from the Vehkamäki et al. [2002] scheme. For the test cases discussed here we obtained initial conditions from a CTM simulation that included a prediction of sulfate mass, but did not include a prediction of sulfate gas (see section 3.1). Thus the partitioning of sulfate between the gas and particulate phase was not available. For our test cases, we prescribed a constant initial relative acidity. This, of course, is different than would be the case if the UMaer model were coupled to a CTM, since the sulfate gas concentration would vary depending on the meteorological conditions, the history of an air parcel, and the applied nucleation scheme. Although we compared the UMaer simulations with that from the sectional model using other nucleation schemes, the comparisons were similar to those shown here. Therefore we do not examine the consequences of these different schemes here but plan to examine them within the context of the GRANTOUR CTM [Penner and Herzog, 2002].

[18] The Vehkamäki et al. [2002] scheme provides a consistent set of parameterizations for the sulfuric acid saturation pressure, the surface tension, the density, composition and mass of the critical nucleus and the homogeneous nucleation rate. The parameterizations are in agreement with available experimental data for a broad range of environmental conditions $(230.15 \mathrm{~K}<\mathrm{T}<$ $305.15 \mathrm{~K}$ and $1 \%<\mathrm{RH}<100 \%$ ). In addition, the nucleation rates from the parameterization agree with the nucleation rates from the calculations of the full classical theory for temperatures larger than $190 \mathrm{~K}$. To extend this parameterization to even lower temperatures and relative humidities we applied the calculated the nucleation rate for the lowest value of temperature $(\mathrm{T}=190 \mathrm{~K}$ ) or relative humidity $(\mathrm{RH}=1 \%)$ for which the parameterization is valid if the actual temperature or relative humidity fell below these values.

[19] For the surface tension of sulfuric acid solutions we apply the parameterizations given by Vehkamäki et al.
[2002]. The saturation vapor pressure for pure water is calculated according to Preining et al. [1981]. The saturation vapor pressure of pure sulfuric acid follows Ayers et al. [1980] with the low-temperature correction taken from Kulmala and Laaksonen [1990].

\subsubsection{Sulfate Aerosol Composition and Size}

[20] When a particle is formed by homogeneous nucleation we assume that it instantaneously adjusts to the composition given in the parameterization developed by Tabazadeh et al. [1997] for water uptake or release. This parameterization for the sulfuric acid aerosol composition is valid for temperatures between $185 \mathrm{~K}$ and $260 \mathrm{~K}$ and relative humidities larger than $1 \%$. The aerosol composition is given as the sulfate mass fraction in a particle. For temperatures and relative humidities outside this range we use the values predicted by the upper or lower limits for temperature or relative humidity. Size-dependent effects of the aerosol composition are ignored in this parameterization.

[21] The number of sulfate molecules per particles can be calculated from the predicted mass and number concentration in each mode. The mean mass of particles in each mode after water uptake is derived from the sulfate mass fraction and the molecular weight. The particle density for a given composition and temperature is calculated according to the parameterization given by Vehkamäki et al. [2002]. The particle size after water uptake can be derived from the particle mass and its density. This particle size is used in all size-dependent processes in the model.

\subsubsection{Condensation and Evaporation}

[22] A particle can grow in size by the mass transfer of gaseous sulfate to its surface followed by condensation of the gas at the particle surface. Condensational growth takes place as long as the number concentration of sulfate molecules in the gas phase $N_{\text {gas }}$ is larger than the equilibrium gas phase concentration $N_{\text {gas }}^{\text {equ }}$. $\left(N_{\text {gas }}\right.$ and $N_{\text {gas }}^{\text {equ }}$ have units of number of sulfate molecules per volume air). The condensational growth process is limited by the diffusion of gas molecules to the particle surface and proportional to the particle number and size (i.e., to the surface area in the kinetic regime and to the radius in the continuum regime). Condensation increases the mass $M_{p}$ in the particulate phase (in units of number of sulfate molecules per volume air). Under the assumption of spherical particles, condensational growth in each mode can be described by

$$
\begin{gathered}
\frac{\partial}{\partial t} N_{\text {gas }}=-4 \pi \alpha \beta D\left(N_{\text {gas }}-N_{\text {gas }}^{\text {equ }}\right) \overline{r_{p}} N_{p} \\
\frac{\partial}{\partial t} M_{p}=-\frac{\partial}{\partial t} N_{\text {gas }}
\end{gathered}
$$

with

$$
\begin{gathered}
\alpha=\exp \left(-\ln ^{2} \sigma_{g}\right) \\
\beta=\left[1+\left(\frac{1.33 K n+0.71}{1+K n}+\frac{4(1-\epsilon)}{3 \epsilon}\right) K n\right]^{-1} \\
K n=\frac{\lambda}{\overline{r_{p}}} \\
N_{\text {gas }}^{\text {equ }}=\gamma X \exp \left(\frac{2 \sigma_{p} m_{p}}{R^{*} T_{\rho_{p}}}{\overline{r_{p}}}^{-1}\right) N_{\text {gas }}^{\text {sat }}
\end{gathered}
$$


$N_{p}$ and $\overline{r_{p}}$ are the particle number concentration and the volume mean radius of a given mode, respectively. $\alpha$ is dimensionless and corrects for the effect of the size distribution on the condensation rate. $\sigma_{g}$ is the geometric standard deviation of the lognormal distribution of a given mode. Here $\alpha$ is calculated based on the assumption that the condensation rate is proportional to the particle size. Hence $\alpha$ ignores the size dependence of the Knudson number $K n$ and of the saturation vapor pressure over a curved surface.

[23] Here $\beta$ is the correction factor for noncontinuum effects and imperfect surface accommodation [Fuchs and Sutugin, 1971; Seinfeld and Pandis, 1997]. We assume a unity accommodation coefficient $\varepsilon$ in the test calculations reported below. However, in the code $\varepsilon$ can be specified for each mode individually. $\lambda$ denotes the mean free path for $\mathrm{H}_{2} \mathrm{SO}_{4}$ molecules in air. $\lambda$ and the diffusion coefficient $D$ for $\mathrm{H}_{2} \mathrm{SO}_{4}$ molecules in air depend on the ambient temperature and pressure [Chapman and Cowling, 1970; Davis, 1983].

[24] The equilibrium gas phase concentration $N_{\text {gas }}^{\text {equ }}$ over a particle depends on the activity coefficient for sulfate $\gamma$, the sulfate mole fraction $X$ and the saturation concentration $N_{\text {gas }}^{\text {sat }}$ of pure sulfuric acid over a flat surface. For $\gamma$ we use the parameterization given by Taleb et al. [1996]. The parameterization for $X$ assumes an equilibrium of sulfate aerosol particles with the ambient water vapor [Tabazadeh et al., 1997]. The Kelvin or curvature effect is described by

$$
\exp \left(\frac{2 \sigma_{p} m_{p}}{R^{*} T \rho_{p}}{\overline{r_{p}}}^{-1}\right)
$$

and depends on the particle properties such as surface tension $\sigma_{p}$, molecular weight $m_{p}$, density $\rho_{p}$ and radius $\overline{r_{p}}$ [Seinfeld and Pandis, 1997]. $T$ denotes the in situ temperature, $R^{*}$ the universal gas constant. Evaporation creates smaller particles which eventually disappear completely.

\subsubsection{Coagulation}

[25] Coagulation occurs when two particles collide and stick together, reducing the number concentration but conserving the mass and volume concentration of particles in the atmosphere. Two particles can coagulate due to their (random) Brownian motion, due to a difference in fall velocity (gravitational collection) or due to turbulent effects of the flow (turbulent inertial motion and turbulent shear). Only Brownian coagulation is considered here since it dominates coagulation for particles with radii in the submicron range [Seinfeld and Pandis, 1997].

[26] For Brownian motion three different flow regimes need to be considered: the continuum, the free molecular, and the transition regime. In the continuum regime the particle radius $r$ is large compared to the mean free path of air molecules $\lambda_{\text {air }}$ and the particle motion is determined by the air viscosity. In the free molecular regime $\left(r \ll \lambda_{\text {air }}\right)$ the particle motion is governed by the inertia of air molecules hitting the particle. In the transition regime $r$ and $\lambda_{\text {air }}$ are of the same order.

[27] In order to describe particles in all three flow regimes we apply the interpolation formula of Fuchs [1964] for the coagulation kernel:

$$
\begin{aligned}
K_{i j}= & 4 \pi\left(D_{i}+D_{j}\right)\left(r_{i}+r_{j}\right) \\
& \cdot\left(\frac{r_{i}+r_{j}}{r_{i}+r_{j}+\left(\delta_{i}^{2}+\delta_{j}^{2}\right)^{1 / 2}}+\frac{4\left(D_{i}+D_{j}\right)}{\left(v_{i}^{2}+v_{j}^{2}\right)^{1 / 2}\left(r_{i}+r_{j}\right)}\right)^{-1}
\end{aligned}
$$

with

$$
\begin{gathered}
D_{i}=\frac{k_{B} T}{6 \pi \eta_{\text {air }} r_{i}}\left[1+K n_{i}\left(1.249+0.42 \exp \left(-\frac{0.87}{K n_{i}}\right)\right)\right] \\
K n_{i}=\frac{\lambda_{\text {air }}}{r_{i}} \\
\delta_{i}=2 \frac{\left(r_{i}+l_{i}\right)^{3}-\left(r_{i}^{2}+l_{i}^{2}\right)^{3 / 2}}{3 r_{i} l_{i}}-2 r_{i} \\
l_{i}=\frac{4 D_{i}}{\pi v_{i}} \\
v_{i}=\left(\frac{8 k_{B} T}{\pi m_{i}}\right)^{1 / 2}
\end{gathered}
$$

The coagulation kernel $K_{i j}$ describes the collision probability of two particles with radii $r_{i}$ and $r_{j} . D_{i}$ is the particle diffusion coefficient with Cunningham slip factor. $l_{i}$ and $v_{i}$ are the particle mean free path and thermal velocity, respectively. $k_{B}, T$ and $K n_{i}$ denote the Boltzmann constant, the in situ temperature and the Knudson number, respectively. The mean free path of air molecules $\lambda_{\text {air }}$ depends on pressure and temperature [Seinfeld and Pandis, 1997]. For the dynamic viscosity $\eta_{\text {air }}$ we use the temperaturedependent Sutherland's equation [List, 1984].

[28] In our approach we apply the volume mean radius of each mode in equation (3). As previously discussed the humidity growth is taken into account when calculating the volume mean radius. Coagulation can occur between particles of the same mode (intramodal coagulation) and between particles of different modes (intermodal coagulation).

[29] Intramodal coagulation reduces the number concentration per volume air $N_{i}$ of mode $i$ over a time step $d t$ according to:

$$
\frac{\partial}{\partial t} N_{i}=-0.5 K_{i i} N_{i}^{2} d t
$$

[30] Intermodal coagulation removes particles from a mode $i$ with smaller volume mean radius and adds their mass to a mode $j$ with larger volume mean radius. The particle number change in mode $i$ is given by:

$$
\frac{\partial}{\partial t} N_{i}=-\sum_{j>i} K_{i j} N_{i} N_{j} d t
$$

The mass transferred from mode $i$ to mode $j$ is given by

$$
\frac{\partial}{\partial t} M_{i}=-\sum_{j>i} K_{i j} M_{i} N_{j} d t
$$

\subsubsection{Gravitational Settling}

[31] Aerosol particles are removed from the atmosphere by gravitational settling, and wet and dry deposition. These processes are typically part of a transport model and are not 
described by the dynamics of the aerosol population. For the test cases presented below, however, we included gravitational settling as a loss mechanism. Since gravitational settling is strongly size-dependent these tests allow for an additional evaluation of the representation of the aerosol size distribution in our model.

[32] The gravitational settling velocity of an aerosol particle with radius $r_{p}$ follows the Stokes law with Cunningham slip correction factor [Seinfeld and Pandis, 1997]:

$$
v_{\text {grav }}=\frac{2}{9} \frac{g}{\eta_{\text {air }}} r_{p}^{2} \rho_{p}\left\{1+K n\left[1.257+0.4 \exp \left(-1.1 K n^{-1}\right)\right]\right\}
$$

with

$$
K n=\frac{\lambda_{\text {air }}}{r_{p}}
$$

If one neglects the size dependence of the Cunningham slip correction, the settling velocity is proportional to the square of the particle radius. Hence, for a mode of lognormally distributed particles the effective radius for gravitational settling is

$$
r_{\text {eff }}=r_{g} \exp \left(\ln ^{2} \sigma_{g}\right)
$$

where $r_{g}$ and $\sigma_{g}$ are the geometric radius and standard deviation, respectively. The geometric radii for the particle number distribution and particle mass distribution of the same mode differ by a factor exp $\left(3 \ln ^{2} \sigma_{g}\right)$. The effective radii for mass and number concentration can be expressed in terms of the volume mean radius according to $\overline{r_{v o l}}$.

$$
\begin{gathered}
r_{e f f}^{n u m}=\overline{r_{v o l}} \exp \left(-0.5 \ln ^{2} \sigma_{g}\right) \\
r_{e f f}^{\text {mass }}=\overline{r_{v o l}} \exp \left(2.5 \ln ^{2} \sigma_{g}\right)
\end{gathered}
$$

In order to derive a loss rate for gravitational settling in our box model calculations we arbitrarily assumed a box height of $d z=65 \mathrm{~m}$.

[33] The mean loss rates due to gravitational settling over a time step $d t$ for the mass and number concentration in each mode $i$ are

$$
\begin{aligned}
\frac{\partial}{\partial t} M_{i} & =-\overline{v_{\text {grav }}^{\text {mass }}} d z M_{i} d t \\
\frac{\partial}{\partial t} N_{i} & =-\overline{v_{\text {grav }}^{\text {num }}} d z N_{i} d t
\end{aligned}
$$

\subsubsection{Chemical Sources and Cloud Processing}

[34] Atmospheric sulfate is produced by the oxidation of the precursor gases $\mathrm{DMS}, \mathrm{SO}_{2}$ and $\mathrm{H}_{2} \mathrm{~S}$ in the gas or aqueous phase. In our aerosol box model we apply constant source rates for the production of gas phase and aqueous phase sulfate. The source rates are derived from a simulation of present-day sulfate aerosol burden using the GRANTOUR CTM [Walton et al., 1988; Penner et al., 2001, 2002].

[35] Sulfate produced in the aqueous phase increases the mass of particles that have acted as cloud condensation nuclei $(\mathrm{CCN})$. $\mathrm{CCNs}$ are either scavenged by precipitation or released back to the atmosphere when the cloud droplets evaporate. In our model calculations we assume that all soluble aerosol particles larger than $0.1 \mu \mathrm{m}$ in diameter may act as CCNs.

\subsubsection{Merging}

[36] The mean particle size of each mode changes with time due to the processes of condensation and coagulation. Because of this and the width of the mode, particle growth can lead to a substantial overlap between the size distributions of different modes. As a consequence, these overlapping modes represent a similar particle size range which leads to a poor representation of the total aerosol size distribution by the available number of modes in the model.

[37] In addition, for coagulation we assume that the modes are ordered by size: particles in the first mode have a smaller mean size than particles in the second mode, particles in the second mode are smaller than in the third mode, and so on. With no additional restrictions, the modes can eventually change their order in size thereby violating the assumptions made in the formulation of coagulation.

[38] In order to maintain a good representation of the aerosol size distribution with the available number of modes and to enforce the ordering of modes by size, the mean size of each mode is only allowed to vary within a certain size range. If the size distribution of a mode contains a significant number of particles that are larger than a predefined limit radius for this mode the number and mass of particles larger than this limit are transferred to the next mode.

[39] In the code this merging is implemented by using a table lookup. During the model initialization, we calculate the mean particle radius for each mode. This, together with the fixed width of the lognormal representation in that mode, determines the percentage of particles in each mode that are larger than the limit radius. In the current implementation, merging takes place if more than $2.5 \%$ of all particles in a mode are larger than the specified limit radius. The table lookup tells us how many particles and how much mass needs to be transferred to the next mode. Our merging process conserves aerosol mass and number. However, because of the constant width assumption the surface concentration is not conserved when merging takes place.

\subsection{Interaction Between Sulfate and Nonsulfate Aerosol Components}

[40] Sulfate gas can condense on both sulfate and nonsulfate preexisting aerosol particles and sulfate particles can coagulate with both. In the model we assume a fixed size distribution for dry nonsulfate aerosol particles. The number of nonsulfate aerosol components as well as their particle density and size are specified during the model initialization. The size distribution of each non sulfate aerosol component is represented by a superposition of up to 3 lognormal distributions. Nonsulfate aerosol particles can change their size due to humidity growth and due to the uptake of sulfate. Sulfate may attach to non sulfate aerosol particles through condensation, coagulation or cloud processing.

[41] Gaseous sulfate can condense onto the surface of preexisting nonsulfate aerosol particles. The accommodation coefficients can be specified for each component separately and were set to unity in this study. The condensation and evaporation rates are calculated according to 
equations (1) and (2) applying the proper values for the particle size, number and width parameter. For the Kelvin effect we assume that the nonsulfate aerosol particles are covered with at least a monolayer of sulfate.

[42] Coagulation between the predicted sulfate aerosol modes and nonsulfate aerosol particles reduces the mass and the number of pure sulfate aerosol particles. Coagulation between nonsulfate aerosol particles of the same or of a different type is not included in the model at this point. The intermodal coagulation rates between sulfate and nonsulfate aerosol modes are calculated according to equations (5) and (6).

[43] Nonsulfate aerosol particles in the accumulation mode can act as CCN (cloud condensation nuclei). Sulfate formed in cloud droplets by oxidation of $\mathrm{SO}_{2}$ increases the mass of each CCN. Hence sulfate from aqueous chemistry is equally distributed among all accumulation mode particles including particles from non sulfate aerosol components.

\subsection{Advancing the Solution in Time}

[44] The solution of the equations is advanced in time using a fourth-order Runge-Kutta scheme with a dynamically adjusted time step [Press et al., 1986]. Over each time period of interest which can be aligned to the time step of a chemical transport model, for example, and is termed the outer time step here an inner time step is defined by subdividing the time period of interest into smaller time steps using the following procedure. At the beginning of the outer time step an initial guess for the first inner time step is calculated based on the initial time derivatives of all processes that are described in the previous subsections. All prognostic variables are advanced twice in time: applying the full time step once and applying half the time step twice. By combining both solutions the scheme becomes fifth order accurate [Press et al., 1986]. A numerical error of the time integration is estimated by comparing both solutions. On the basis of this error a new inner time step is calculated for the next advancement in time, if the numerical error is below a certain threshold. If the numerical error exceeds the threshold, the previous time step is repeated with a shorter time step. In the model the error estimate is based on a relative difference between the two solutions. In the simulation performed for this study we require that this difference is smaller than $5 \%$.

[45] In a CTM, calculations must be performed at every grid point. During one time step of the CTM, each grid point is treated as an independent box. Our time aerosol module is designed to treat a certain number of boxes simultaneously. This number can be adjusted for optimal performance on a specific computer and does not have to be identical with the total number of grid points in the CTM. Although multiple boxes are treated simultaneously the inner time step in the aerosol model is calculated for each box individually. During a strong nucleation event, the time step can be shorter than $1 \mathrm{~s}$. If nucleation is not active, time steps of several hours are possible.

\section{Comparison With a Sectional Model}

[46] For validation we compared the UMaer model with the sectional Atmospheric Environmental Research (AER) model [Weisenstein et al., 1997]. In the standard configu- ration the AER model treats 40 size bins for sulfate aerosol. A fixed time step of 30 minutes is applied (with smaller time steps for nucleation). For this comparison we increased the number of size bins in the AER model to 150 bins to reduce the effect of numerical diffusion between different size bins. In addition, we reduced the time step in AER to $3.6 \mathrm{~s}$ to minimize numerical errors due to the use of an explicit time step procedure in case of strong nucleation events.

[47] Because the AER model only treats pure sulfate aerosol, the interaction between sulfate and nonsulfate aerosols in UMaer was switched off. However, for comparison, we evaluated the effect of nonsulfate aerosol on the simulated sulfate aerosol distribution. We performed calculations with two and four sulfate aerosol modes (subsequently labeled UMaer(2) and UMaer(4)) to determine the optimal number of modes in UMaer. The simulation that included nonsulfate aerosol included four sulfate aerosol modes plus six nonsulfate aerosol components (subsequently labeled UMaer(4+6)).

[48] In UMaer(2) merging takes place when the size distribution of the smaller mode contains particles that are larger than $0.05 \mu \mathrm{m}$. In the versions with four sulfate aerosol modes the critical radii associated with merging are $0.005 \mu \mathrm{m}, 0.05 \mu \mathrm{m}$ and $0.5 \mu \mathrm{m}$ for the first, second, and third mode, respectively.

\subsection{Initial Conditions}

[49] We selected a total of 360 test cases from a simulation of present-day aerosol burden using the GRANTOUR CTM [Walton et al., 1988; Penner et al., 2001; Penner et al., 2002]. The test cases were selected from four different pressure levels ( $850 \mathrm{mbar}, 500 \mathrm{mbar}, 200 \mathrm{mbar}$ and $50 \mathrm{mbar}$ ) for six different days in January and July. We used the conditions at a continental and a maritime location and at locations with extrema in temperature, relative humidity, sulfate concentration, sulfate production rates and nonsulfate aerosol concentrations. This strategy for test cases allows us to cover a large range of initial conditions that are typical of situations encountered in a CTM.

[50] For the initial partitioning of sulfate between the gas and aerosol phase we assumed a relative acidity of $100 \%$. If not enough sulfate was provided by the initial conditions to reach $100 \%$ relative acidity, all available sulfate was put into the gas phase. With a prescribed relative acidity of $100 \%, 65 \%$ of all test cases in $850 \mathrm{mbar}$ and $500 \mathrm{mbar}$ had no preexisting sulfate aerosol. At $200 \mathrm{mbar}$ and $50 \mathrm{mbar}$ this fraction was $17 \%$. The preexisting aerosol follows the size distribution for sulfate aerosol measured by Milford and Davidson [1987]. This size distribution consists of a superposition of three lognormal distributions (see Table 1).

[51] In the UMaer simulation that included the interaction with nonsulfate aerosol particles we used six additional modes for the six different nonsulfate aerosol components in GRANTOUR. For these six additional modes the amount of sulfate that is attached to the corresponding nonsulfate aerosol component is predicted. The nonsulfate aerosol components represent organic and black carbon and two modes each for sea salt and mineral dust, respectively. The size distributions of the dry nonsulfate core follow the fixed lognormal distributions that are listed in Table 1. Sulfate that is attached to nonsulfate aerosol particles increases their 
Table 1. Size Distribution Parameters for Preexisting Particles ${ }^{\mathrm{a}}$

\begin{tabular}{|c|c|c|c|}
\hline Aerosol Component & $\mathrm{N}_{i}$ & $\mathrm{r}_{i}, \mu \mathrm{m}$ & $\sigma_{i}$ \\
\hline Sulfate $^{b}$ & 0.8994 & 0.0210 & 1.514 \\
\hline Sulfate ${ }^{b}$ & 0.1002 & 0.0650 & 1.778 \\
\hline Sulfate $^{\mathrm{b}}$ & 0.0004 & 0.3515 & 1.230 \\
\hline $\mathrm{OC} / \mathrm{BC}^{\mathrm{c}}$ & 0.4286 & 0.005 & 1.50 \\
\hline $\mathrm{OC} / \mathrm{BC}^{\mathrm{c}}$ & 0.5714 & 0.080 & 1.70 \\
\hline $\mathrm{OC} / \mathrm{BC}^{\mathrm{c}}$ & 1.e-6 & 2.500 & 1.65 \\
\hline Dust $^{\mathrm{d}}$ & 0.198 & 0.010 & 1.4 \\
\hline Dust $^{\mathrm{d}}$ & 0.802 & 0.045 & 1.6 \\
\hline Dust $2^{\mathrm{d}}$ & 1.0 & 0.275 & 2.5 \\
\hline Sea salt $1^{\mathrm{e}}$ & 1.0 & 0.035 & 1.92 \\
\hline Sea salt $2^{\mathrm{e}}$ & 1.0 & 0.350 & 1.70 \\
\hline
\end{tabular}

${ }^{\mathrm{a}} \mathrm{N}_{i}$ is the normalized by the total number concentration, $\mathrm{r}_{i}$ is the geometric mean radius of the lognormal distribution, and $\sigma_{i}$ is its geometric standard deviation.

${ }^{\mathrm{b}}$ Chuang et al. [1997].

${ }^{\mathrm{c}}$ Penner et al. [1998].

${ }^{\mathrm{d}}$ de Reus et al. [2000].

${ }^{\mathrm{e}}$ Quinn et al. [1995].

size. In addition, humidity growth of sea salt particles, biomass aerosols, and the effect of the attached sulfate aerosol is taken into account.

[52] A relative acidity of $100 \%$ means a saturation with respect to pure sulfuric acid. However, the saturation pressure over a $\mathrm{H}_{2} \mathrm{O}-\mathrm{H}_{2} \mathrm{SO}_{4}$ solution is significantly lower than over the pure acid. Therefore a nucleation event is likely to occur at the beginning of the simulation. The strength and the duration of the nucleation event will depend on the competition between nucleation and condensation to reduce the relative acidity. Subsequent coagulation will play an important role in determining the total aerosol number concentration. We performed simulations for 10 days in our test cases. Here we discuss the results after one day of simulation. We used the parameterization of nucleation given by Vehkamäki et al. [2002] for these test cases. The initial number concentrations of sulfate molecules in the gas phase vary between $3.4 \times 10^{-4}$ and $1.6 \times 10^{+10}$ molecules per $\mathrm{cm}^{3}$, with the highest concentrations in the lower troposphere. This range was tested in order to allow a full set of conditions to be examined at all altitudes. For example, at $850 \mathrm{mbar} 40 \%$ of the test cases have initial nucleation rates of less than $1 \mathrm{~cm}^{-3} \mathrm{~s}^{-1}$.

[53] Important characteristics of an aerosol population are the total number concentration, the surface area concentration and the number of accumulation mode particles. The surface area is important for chemical reactions on aerosol surfaces. The accumulation mode particles can act as CCN (cloud condensation nuclei) and are the most efficient particles in scattering solar radiation. Here we define the accumulation mode as the aerosol particles with a radius larger than $0.05 \mu \mathrm{m}$ and smaller than $10 \mu \mathrm{m}$.

\subsection{Total Aerosol Number Concentration}

[54] Figure 1 shows scatterplots of the comparison of the predicted total aerosol number concentration in the UMaer and AER models. Figure 1a is a comparison of the Umaer particle number concentration with that from AER when the mass and number concentration of four sulfate aerosol modes is predicted. Since the number concentrations in the different test cases span a range of over six orders of magnitude, the results are plotted on a double logarithmic scale. Each data point represents one test case. If there were perfect agreement, the data points would lie along the main diagonal. The other secondary diagonals mark differences of a factor of 2, 10 and 1000, respectively. On average, the agreement in the total aerosol number between the two models is better than a factor of two. At 200 mbar, there are a significant number of cases ( 8 out of 90) that do not agree within a factor of two. However, these cases generally agree within one order of magnitude.

[55] A measure $\chi$ for the scatter between two models can be obtained from the standard deviation of the distance to the main diagonal in log space. Taking the logarithm
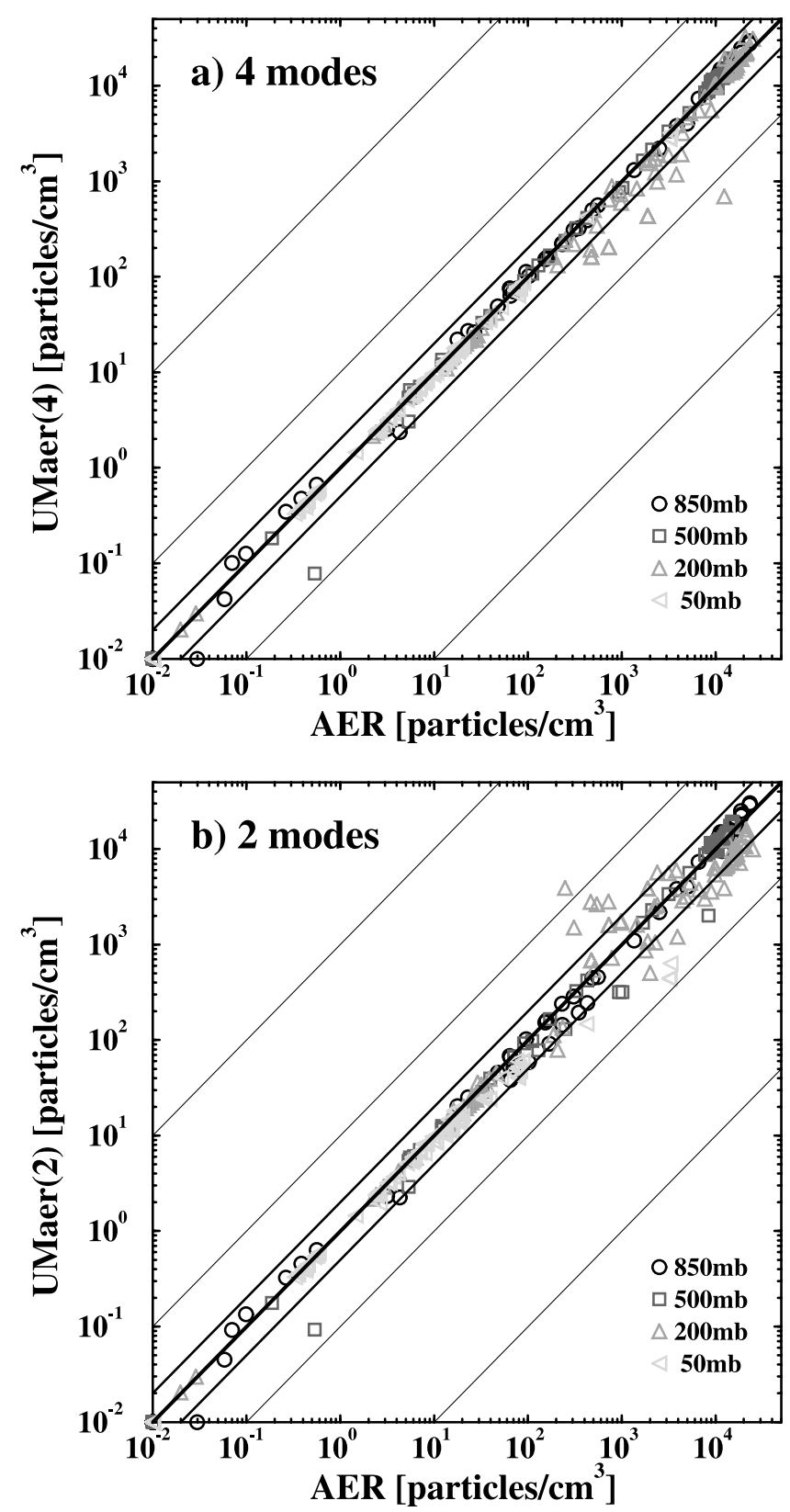

Figure 1. Comparison of total number concentration after 1 day in UMaer and AER for two different configurations of the UMaer model. See color version of this figure at back of this issue. 
Table 2. Agreement Between Different Model Configurations ${ }^{\mathrm{a}}$

\begin{tabular}{|c|c|c|c|c|c|}
\hline & $850 \mathrm{mb}$ & $500 \mathrm{mb}$ & $200 \mathrm{mb}$ & $50 \mathrm{mb}$ & All \\
\hline \multicolumn{6}{|l|}{ Total aerosol number } \\
\hline UMaer(4) - AER & 1.11 & 1.16 & 1.37 & 1.03 & 1.21 \\
\hline UMaer(2) - AER & 1.14 & 1.23 & 1.40 & 1.34 & 1.31 \\
\hline \multicolumn{6}{|l|}{ Aerosol surface area } \\
\hline UMaer(4) - AER & 1.20 & 1.13 & 1.11 & 1.03 & 1.14 \\
\hline UMaer(2) - AER & 1.20 & 1.21 & 1.36 & 1.23 & 1.29 \\
\hline \multicolumn{6}{|c|}{ Accumulation mode particles, all cases } \\
\hline UMaer(4) - AER & 2.10 & 5.98 & 1.28 & 1.07 & 2.93 \\
\hline UMaer(2) - AER & 2.12 & 5.83 & 1.58 & 1.10 & 2.91 \\
\hline \multicolumn{6}{|c|}{ Accumulation mode particles, filtered cases } \\
\hline UMaer(4) - AER & 1.13 & 1.31 & 1.13 & 1.07 & 1.16 \\
\hline UMaer(2) - AER & 1.48 & 1.45 & 1.56 & 1.10 & 1.46 \\
\hline
\end{tabular}

${ }^{\mathrm{a}}$ The values $(\mathrm{X})$ are calculated from the standard deviation of the distance to the main diagonal in log space. Here $\mathrm{X}=1$ means no scatter, all data point are on a perfect straight line. $\chi=2$ means an agreement within a factor of two. The filtered cases only include cases for which the AER versions with 40 and 150 size bins agree within a factor of 2 .

gives cases with low and high number concentrations a similar weight and the standard deviation reduces the influence of single outliers. If there is a perfect agreement $\chi=1$. If the considered cases agree on average within a factor of 2 , then $\chi=2$. An agreement within one order of magnitude gives $\chi=10$. The quantity $\chi$ is listed in Table 2 for the total number concentration and for different model configurations. For UMaer(4) $\chi$ is significantly smaller than two at all pressure levels.

[56] When only two modes are used in UMaer to represent sulfate aerosol the scatter between UMaer and AER is increased by $20 \%$ to $30 \%$. However, as shown in Table 2 the models still agree to better than a factor of 1.4. The main reason for the increase in scatter is that in UMaer(4) new particles from homogeneous nucleation are not mixed with the Aitken mode particles as in UMaer(2) but are considered by a separate mode. Hence, in UMaer(4) coagulation and consequently the total number concentrations are in better agreement with the AER sectional model. On average, when all levels are considered, the four-mode model agrees with the AER model to within a factor of 1.2, while the two-mode model agrees to within a factor of 1.3 .

\subsection{Surface Area Concentration}

[57] Figure 2 shows scatterplots of the surface area concentration for two different model configurations. There is very good agreement in the predicted aerosol surface area between UMaer(4) and AER (see Figure 2a). Except for one case with a very low surface area concentration the results for all test cases differ by less than a factor of 2 .

[58] Because coagulation is systematically underpredicted with only 2 modes, UMaer(2) produces smaller particles on average than does UMaer(4), so that the surface area concentration tends to be overpredicted in UMaer(2) (see Figure 2b). This effect is largest for the test cases at 200 mbar where the surface area in UMaer(2) is on average twice as large as in AER and UMaer(4). However, all test cases agree to within a factor of 5 and the average agreement is better than a factor of 1.3 for the two-mode model and better than a factor of 1.2 for the four-mode model (see Table 2).

\subsection{Accumulation Mode Particles}

[59] At 50 mbar and 200 mbar, the number of accumulation mode particles in UMaer(4) agrees very well with
AER with $\chi$ values smaller then 1.5 (Table 2). However, as shown in Figure 3a, UMaer(4) predicts a significant number of accumulation mode particles for several cases at 500 mbar and 850 mbar whereas AER predicts no or significantly fewer accumulation mode particles. For these outliers (approximately $20 \%$ of all cases at 500 mbar and 850 mbar) the accumulation mode particles are in the tail of the size distribution. These are difficult cases to resolve for a sectional model unless the chosen bin resolution is sufficiently narrow. When we compared the 40-bin version of the AER model to the 150-bin version, substantial differences occurred for these cases. For example, Figure $4 \mathrm{a}$ shows a comparison with both the 150-bin version of the AER model and the 40-bin version. The 40-bin model version has substantially more particles in the tail of the size distribution. For these outlier cases the number concentration after one day is dominated by the coagulation of particles formed by the initial homogeneous nucleation burst. The size distribution is the result of a growth and a broadening of the initially monodisperse particles. The comparison of the two- and four-mode UMaer model and the sectional model with the AER model is also shown. The number of modes in the UMaer model does not matter in this case. The UMaer model is able to reproduce the mean particle growth. However, the prescribed constant width parameter for the modes in UMaer is larger than the width of the size distribution predicted by the 150-bin version of the AER model.

[60] If only two modes are used the scatter between the results from UMaer and AER increases especially for the test cases at 200 mbar (see Figure 3b). Figure 4b shows an example where UMaer(4) reproduces the bimodal distribution simulated by AER very nicely whereas UMaer(2) overpredicts the mean size for its two modes (especially for the smallest mode). As a consequence the number of accumulation mode particles in UMaer(2) is 5 times larger than in UMaer(4) and AER for this particular test case.

[61] Table 2 shows the $\chi$ statistic for the number of accumulation mode particles for all cases (relative to the 150-bin AER model) and for only those cases where the 40-bin and 150-bin models agree to within a factor of two. The UMaer model is within a factor of 1.5 on average of reproducing the AER result when only those cases in which the 40-bin and 150-bin AER models agree 

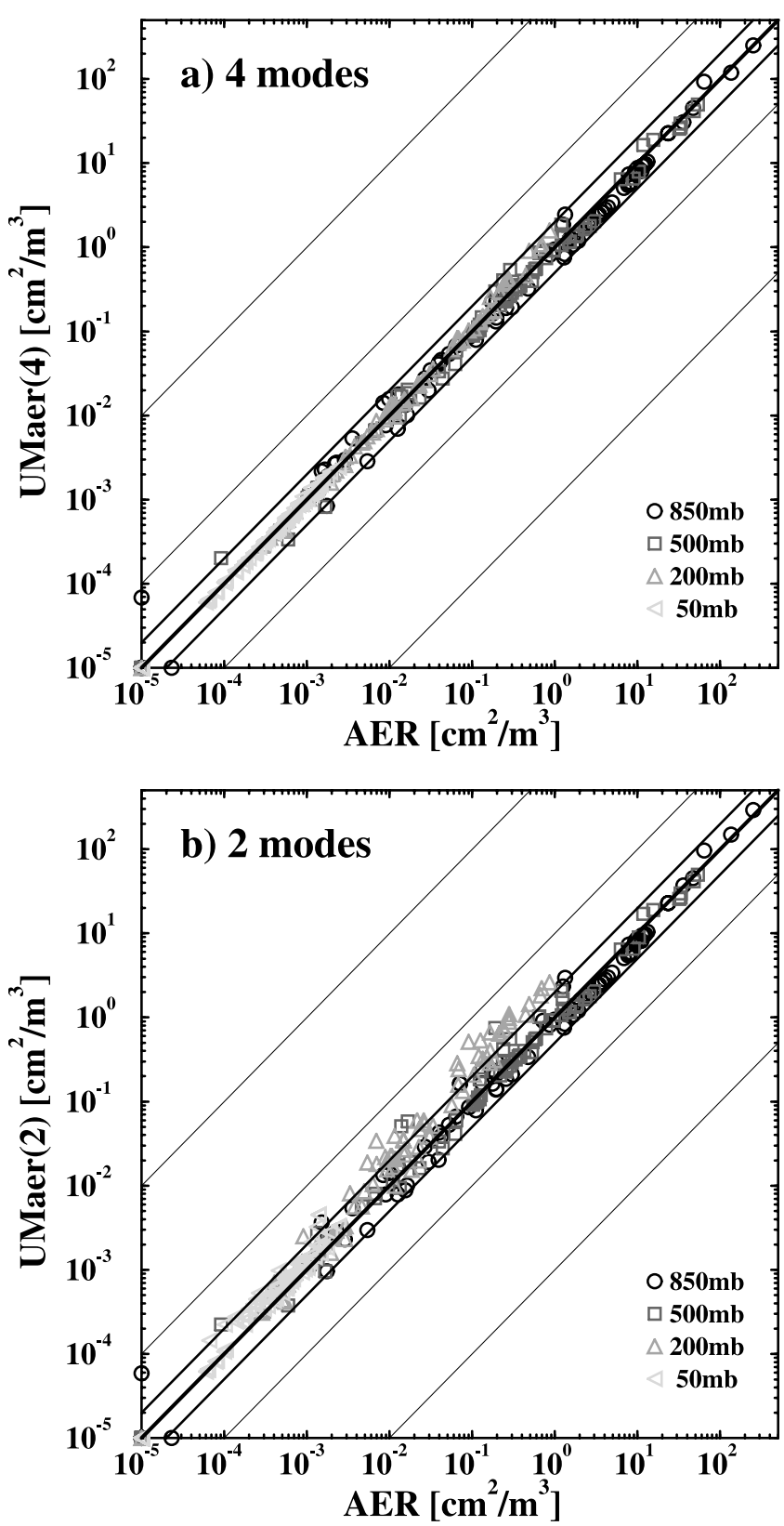

Figure 2. Comparison of surface area concentration after 1 day in UMaer and AER. See color version of this figure at back of this issue.

to within a factor of two are included (i.e., the filtered cases). However, if the difficult cases where even the 40-bin and 150-bin models disagree are also included, the UMaer model results are significantly degraded.

\section{Effect of Nonsulfate Aerosol Components}

[62] Figure 5 shows a comparison of the properties of sulfate aerosol particles if nonsulfate aerosol particles are allowed to interact with the sulfate aerosol dynamics. This comparison quantifies the differences between a model that only treats sulfate aerosols as either a single aerosol component or as an externally mixed component and one that treats the development of an internally mixed aerosol through condensation, coagulation, and the production of sulfate in clouds.

[63] If the interaction between sulfate and nonsulfate aerosol is taken into account, the number of pure sulfate aerosol particles is significantly reduced. As shown in Figure $5 \mathrm{a}$, this reduction often reaches several orders of magnitude. In many cases homogeneous nucleation is completely suppressed by the presence of nonsulfate aerosol particles. The scatter between UMaer $(4+6)$ and UMaer(4) which is introduced by the interaction with nonsulfate aerosols is substantially larger than the scatter due to the different model approaches in UMaer and AER (see Figure 1).

[64] The interaction between sulfate and nonsulfate aerosol particles tends to decrease the surface area concentration
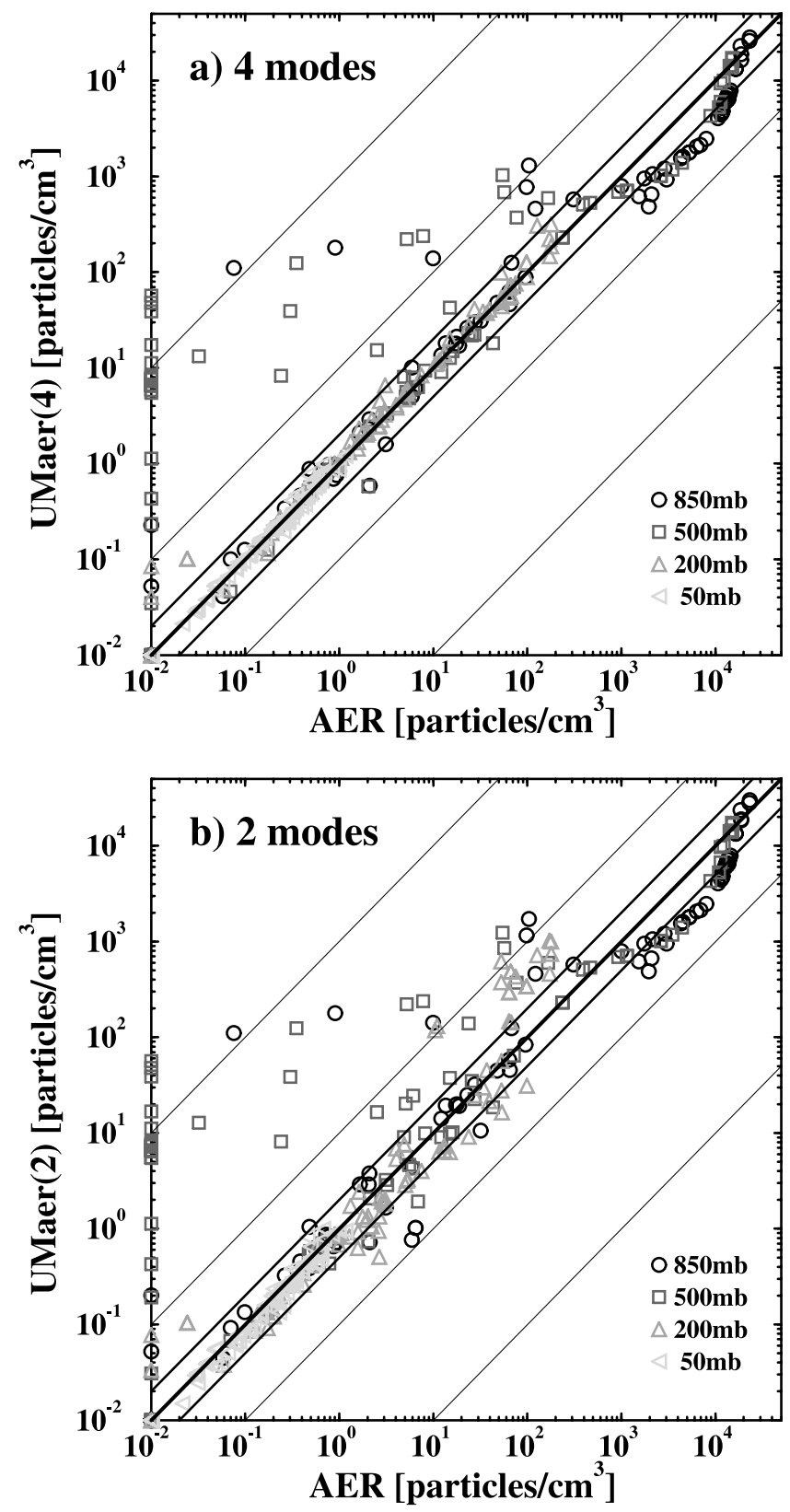

Figure 3. Comparison of accumulation mode particles after 1 day in UMaer and AER. See color version of this figure at back of this issue. 

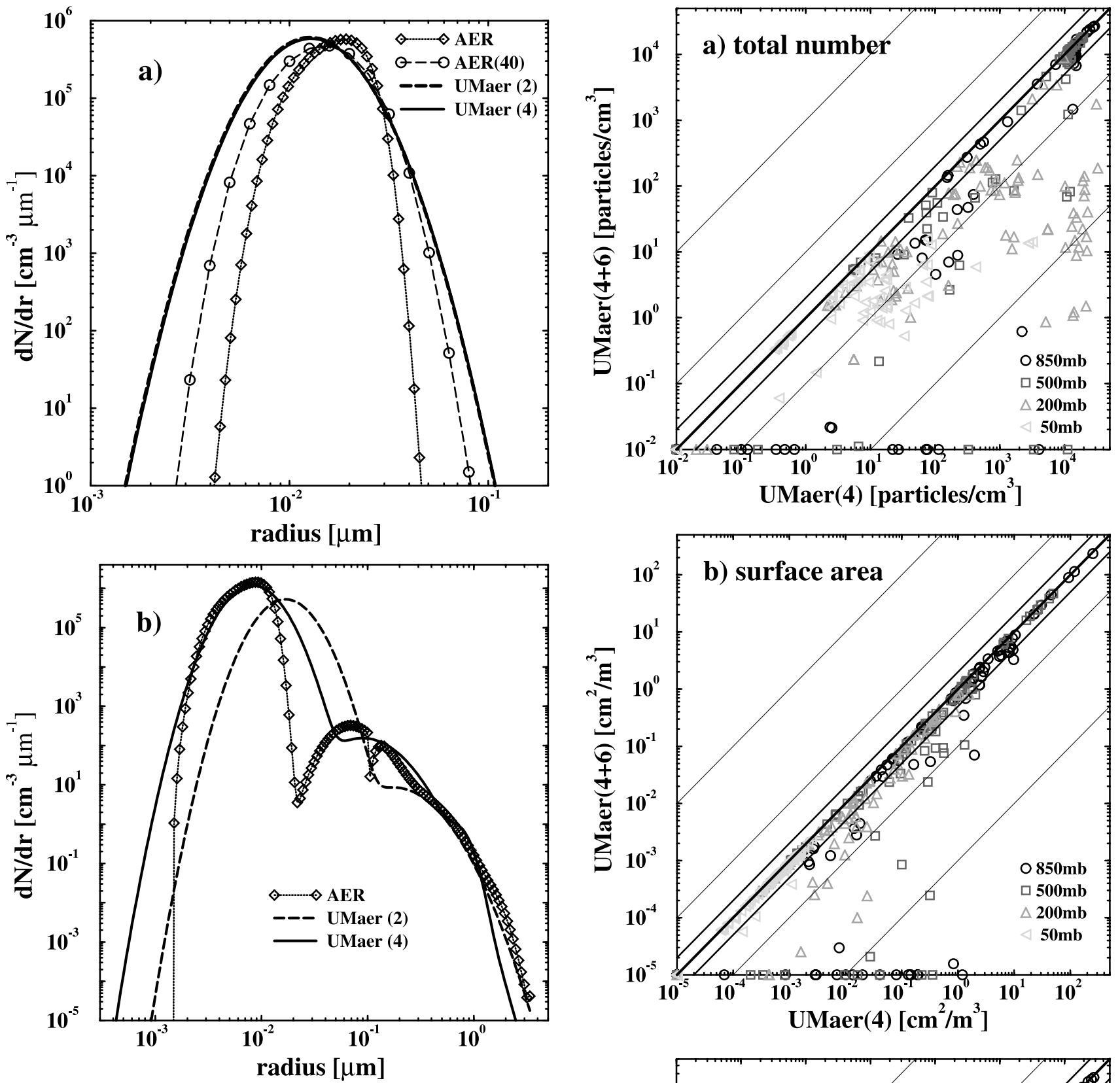

Figure 4. Size distributions for two test cases after 1 day in UMaer and AER.

of pure sulfate aerosol particles (see Figure 5b). However, if the surface of the mixed particles has similar chemical characteristics to pure sulfate particles, the effective sulfate surface area will need to be reevaluated. Although in the majority of test cases UMaer(4 + 6) and UMaer(4) are within a factor of 2 , there are a significant number of test cases with larger changes. For many test cases the surface area concentration in UMaer $(4+6)$ is several orders of magnitude smaller than in UMaer(4). This indicates the

Figure 5. Effect of the interaction of sulfate with nonsulfate aerosol particles on the pure sulfate aerosol size distribution. See color version of this figure at back of this issue.

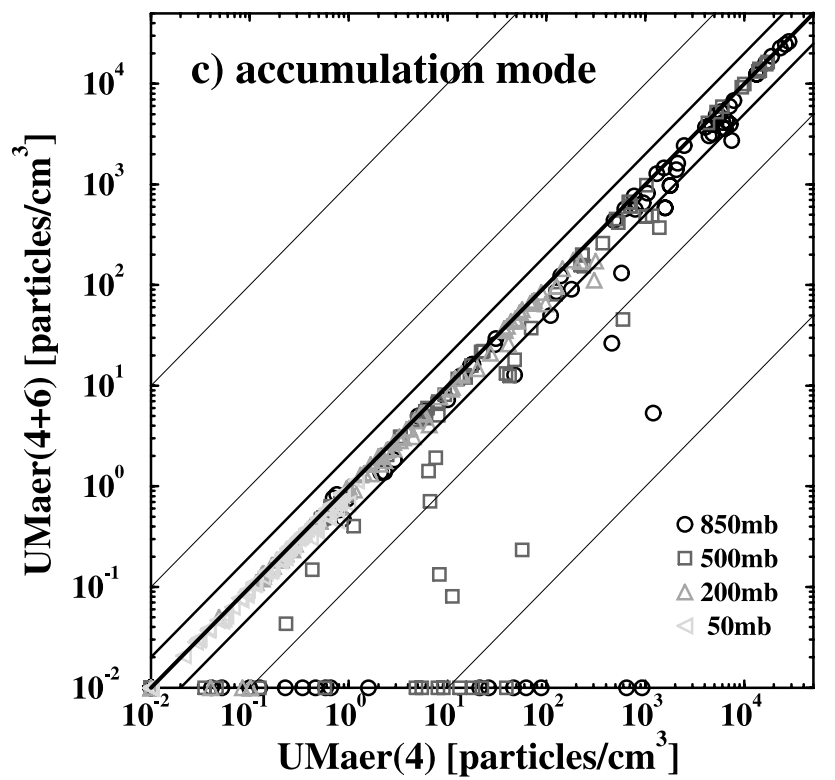


importance of including the interaction between sulfate and nonsulfate aerosols in CTMs.

[65] The number of accumulation mode particles in Figure $5 \mathrm{c}$ is often reduced due to the interaction of sulfate with nonsulfate aerosol particles. However, most of the test cases at 50 mbar and $200 \mathrm{mbar}$ are within a factor of 2 although there is often a much larger difference in the total number concentration in Figure $5 \mathrm{a}$ for the same test case. The large differences in the total number concentrations are caused by differences in the number of small newly nucleated particles that did not grow to the accumulation mode size within one day. For approximately $15 \%$ of the test cases at 500 mbar and $850 \mathrm{mbar}$, the presence of nonsulfate aerosol completely suppresses the growth of pure sulfate aerosol particles into the accumulation mode.

\section{Summary and Discussion}

[66] We have introduced the UMaer aerosol model and shown that it can predict both number concentration and aerosol surface area to within a factor of 1.2 on average in comparison to a sectional model if four modes are used to represent sulfate aerosol dynamics. If only two modes are used, the average prediction is degraded only slightly, to within a factor of 1.3 on average for both number and surface area. The representation of accumulation mode particle number concentration is not as accurate as that for number and surface area. However, the average representation is within a factor of 1.5 for $\operatorname{UMaer}(2)$ and within a factor of 1.2 for UMaer(4) if only those cases where the AER sectional model with 40 bins and 150 bins agree to within a factor of two are considered. In the boundary layer, where the accumulation number concentration determines the aerosol scattering and absorption coefficient, the predicted accumulation mode particle number in the UMaer model is within a factor of 2.1 of that predicted by the 150-bin sectional model for all cases considered here for both the two- and four-mode versions of UMaer.

[67] We were not able to test the nonsulfate version of the UMaer model in comparison to the sectional model. However, the processes of coagulation and condensation have been tested in the sulfate-only case and are expected to be similarly accurate in nonsulfate cases. The predicted changes associated with nonsulfate aerosols are generally larger than the differences between the UMaer(4) or UMaer(2) models for pure sulfate aerosols and the AER model. This indicates the importance of including these interactions in a CTM.

[68] The two-mode version of the UMaer model has been added to the GRANTOUR global model [Penner and Herzog, 2002]. The specific computer resources needed to run the model depend on local conditions and vary from parcel to parcel in the global model because of the dynamic adjustment of the time step in each parcel. With a four hour time step about one third of the parcels need only 2 or 3 iterations, two third of all parcels need less than 14 iterations and only less than $2 \%$ of all parcels need more than 100 iterations. We found that overall, addition of this module in the CTM GRANTOUR increased run times by approximately a factor of two over the version of the model that did not predict size distributions.
[69] We anticipate that the further development of the UMaer model to include the prediction of the width of the aerosol size distribution within each mode as well as the prediction of the aerosol number and mass in each mode will improve the agreement between the sectional model and the UMaer model for the number of accumulation particles. However, the present model is able to represent the evolution of the aerosol size distribution to within a factor of 3.5 on average.

[70] The flexible nature of this model makes it easy to consider other nucleation schemes that involve other gas and aerosol components, such as sulfate-mediated organic components [R. Zhang et al., 2004; Kulmala et al., 2004], ion-mediated nucleation [Laakso et al., 2002; Turco et al., 2000], the ternary nucleation of $\mathrm{H}_{2} \mathrm{SO}_{4}, \mathrm{NH}_{3}$ and $\mathrm{H}_{2} \mathrm{O}$ [Napari et al., 2002], and nucleation of biogenic iodide emissions [O'Dowd et al., 2002]. In addition, consideration of secondary organic aerosols [Chung and Seinfeld, 2002] and of $\mathrm{NH}_{4}$ and $\mathrm{HNO}_{3}$ partitioning into the aerosol phase [Adams et al., 2001; Rodriguez and Dabdub, 2004] is straightforward. Future work will consider these mechanisms as well as a comparison of observations to the predictions from this scheme within a global model.

\section{References}

Adams, P. J., J. H. Seinfeld, D. Koch, L. Mickley, and D. Jacob (2001), General circulation model assessment of direct radiative forcing by the sulfate-nitrate-ammonium-water inorganic aerosol system, J. Geophys. Res., 106, 1097-1111.

Ayers, G. P., R. W. Gillet, and J. L. Gras (1980), On the vapor pressure of sulphuric acid, Geophys. Res. Lett., 7, 433-436.

Bates, T. S., B. J. Huebert, J. L. Gras, F. B. Griffiths, and P. A. Durkee (1998), International global atmospheric chemistry (IGAC) project's first aerosol characterization experiment (ACE 1): Overview, J. Geophys. Res., 103, 16,297-16,318.

Binkowski, F. S., and S. J. Roselle (2003), Models-3 community scale air quality model (CMAQ) model aerosol component: 1 . Model description, J. Geophys. Res., 108(D6), 4183, doi:10.1029/2001JD001409.

Chapman, S., and T. G. Cowling (1970), The Mathematical Theory of Nonuniform Gases, Cambridge Univ. Press, New York.

Chuang, C. C., J. E. Penner, K. E. Taylor, A. S. Grossmann, and J. J. Walton (1997), An assessment of the radiative effects of anthopogenic sulfate, J. Geophys. Res., 102(D3), 3761-3778.

Chung, S. H., and J. H. Seinfeld (2002), Global distribution and climate forcing of carbonaceous aerosols, J. Geophys. Res., 107(D19), 4407, doi:10.1029/2001JD001397.

Clarke, A. D., and V. N. Kapustin (2001), A Pacific aerosol survey. Part i: A decade of data on particle production, transport, evolution, and mixing in the troposhere, J. Atmos. Sci., 59, 363-382.

Davis, E. J. (1983), Transport phenomena with single aerosol particles, Aerosol. Sci. Technol., 2, 121-144.

de Reus, M., F. Dentener, A. Thomas, S. Borrmann, J. Stroem, and J. Lelieveld (2000), Airborne observations of dust aerosol over the North Atlantic Ocean during ACE2: Indications for heterogeneous ozone destruction, J. Geophys. Res., 105, 15,263-15,275.

Fitzgerald, J. W., and W. A. Hoppel (1998), A one-dimensional sectional model to simulate multicomponent aerosol dynamics in the marine boundary layer: 1. Model description, J. Geophys. Res., 103, 16,085-16,102.

Fuchs, N. A. (1964), Mechanics of Aerosols, Pergamon, New York.

Fuchs, N. A., and A. G. Sutugin (1971), High dispersed aerosols, in Topics in Current Aerosol Research, vol. 2, edited by G. M. Hidy and J. R. Brock, pp. 1-60, Pergamon, New York.

Gelbard, F., and J. H. Seinfeld (1980), Simulation of multicomponent aerosol dynamics, J. Colloid Interface Sci., 78, 485-501.

Ghan, S. J., R. C. Easter, E. G. Chapman, H. Abdul-Razzak, Y. Zhang, L. R. Leung, N. S. Laulainen, R. D. Saylor, and R. A. Zaveri (2001), A physically based estimate of radiative forcing by anthropogenic sulfate aerosol, J. Geophys. Res., 106, 5279-5293.

Huebert, B. J., T. Bates, P. B. Russell, Y. J. Kim, G. Shi, K. Kawamura, G. Carmichael, and T. Nakajima (2003), An overview of ACE-Asia: Strategies for quantifying the relationships between asian aerosols and their climatic impacts, J. Geophys. Res., 103(D23), 8633, doi:10.1029/ 2003JD003550. 
Jacobson, M. Z. (2001), Global direct radiative forcing due to multicomponent anthropogenic and natural aerosols, J. Geophys. Res., 106, $1551-$ 1568 .

Korhonen, H., K. E. J. Lehtinen, L. Pirjola, I. Napari, and H. Vehkamäki (2003), Simulation of atmospheric nucleation mode: A comparison of nucleation models and size distribution representations, J. Geophys. Res., 108(D15), 4471, doi:10.1029/2002JD003305.

Kulmala, M., and A. Laaksonen (1990), Binary nucleation of water-sulfuric acid system: Comparison of classical theories with different $\mathrm{H}_{2} \mathrm{SO}_{4}$ saturation vapor pressures, J. Chem. Phys., 93, 696-701.

Kulmala, M., A. Laaksonen, and L. Pirjola (1998), Parameterizations for sulfuric acid/water, J. Geophys. Res., 103, 8301-8307.

Kulmala, M., V.-M. Kerminen, T. Anttila, A. Laaksonen, and C. D. O'Dowd (2004), Organic aerosol formation via sulphate cluster activation, J. Geophys. Res., 109, D04205, doi:10.1029/2003JD003961.

Laakso, L., J. M. Mäkelä, L. Pirjola, and M. Kulmala (2002), Model studies on ion-induced nucleation in the atmosphere, J. Geophys. Res., 107(D20), 4427, doi:10.1029/2002JD002140.

List, R. J. (Ed.) (1984), Smithsonian Meteorological Tables, 6th ed., Smithsonian Inst. Press, Washington, D. C.

Malm, W. C., J. F. Sisler, D. Huffman, R. A. Eldred, and T. A. Cahill (1994), Spatial and seasonal trends in particle concentration and optical extinction in the United States, J. Geophys. Res., 99, 1347-1370.

Mebust, M. R., F. S. Binkowski, and S. J. Roselle (2003), Models-3 community multiscale air quality (CMAQ) model aerosol component: 2. Model evaluation, J. Geophys. Res., 108(D6), 4184, doi:10.1029/ 2001JD001410.

Milford, J. B., and C. I. Davidson (1987), The sizes of particulate sulfate and nitrate in the atmosphere-A review, J. Air Pollut. Control Assoc., $37,125-134$

Napari, I., M. Noppel, H. Vehkamäki, and M. Kulmala (2002), Parametrization of ternary nucleation rates for $\mathrm{H}_{2} \mathrm{SO}_{4}-\mathrm{NH}_{3}-\mathrm{H}_{2} \mathrm{O}$ vapors, J. Geophys. Res., 107(D19), 4381, doi:10.1029/2002JD002132.

O’Dowd, C. D., J. L. Jimenez, R. Bahreini, R. C. Flagan, J. H. Seinfeld, K. Hameri, L. Pirjola, M. Kulmala, S. G. Jennings, and T. Hoffmann (2002), Marine aerosol formation from biogenic iodine emissions, Nature, 417, 632-636.

Penner, J. E., and M. Herzog (2002), Changes in sulfate aerosol associated with aqueous chemistry, heterogeneous reactions on aerosol and nucleation, Eos Trans. AGU, 83(47), Fall Meet. Suppl., Abstract A51E-05.

Penner, J. E., C. C. Chuang, and K. Grant (1998), Climate forcing by carbonaceous and sulfate aerosols, Clim. Dyn., 14, 839-851.

Penner, J. E., et al. (2001), Aerosols: Their direct and indirect effects, in Climatic Change 2001: The Scientific Basis, edited by H. T. Houghton et al., pp. 289-348, Cambridge Univ. Press, New York.

Penner, J. E., et al. (2002), A comparison of model- and satellite-derived aerosol optical depth and reflectivity, J. Atmos. Sci., 59, 441-460.

Preining, O., P. E. Wagner, F. G. Pohl, and W. Szymanski (1981), Heterogenous nucleation and droplet growth, technical report, Aerosolforsch am Inst. für Experimentalphys. der Univ. Wien, Vienna.

Press, W. H., B. P. Flannery, S. A. Teukolsky, and W. T. Vetterling (1986), Numerical Recipes, Cambridge Univ. Press, New York.

Quinn, P. K., S. F. Marshall, T. S. Bates, D. S. Covert, and V. N. Kapustin (1995), Comparison of measured and calculated aerosol properties relevant to the direct radiative forcing of tropospheric sulfate aerosol on climate, J. Geophys. Res., 100, 8977-8991.

Raes, F., T. Bates, F. McGovern, and M. van Liedekerde (2000), The 2nd aerosol characterization experiment (ACE-2): General overview and main results, Tellus, Ser. B, 52(2), 484-497.

Rodriguez, M. A., and D. Dabdub (2004), IMAGES-SCAPE2: A modeling study of size- and chemically resolved aerosol thermodynamics in a global chemical transport model, J. Geophys. Res., 109, D02203, doi:10.1029/2003JD003639.

Russell, P. B., P. V. Hobbs, and L. L. Stove (1999), Aerosol porperties and radiative effects in the United States East Coast haze plume: An overview of the Tropospheric Aerosol Radiative Forcing Observational Experiment (TARFOX), J. Geophys. Res., 104, 2213-2222.
Seinfeld, J. H., and S. N. Pandis (1997), Atmospheric Chemistry and Physics, John Wiley, Hoboken, N. J.

Suck, S. H., and J. R. Brock (1979), Evolution of aerosol particle size distributions via Brownian coagulation: Numerical simulation, J. Aerosol Sci., 10, 581-590.

Tabazadeh, A., O. B. Toon, S. L. Clegg, and P. Hamill (1997), A new parameterization of $\mathrm{H}_{2} \mathrm{SO}_{4} / \mathrm{H}_{2} \mathrm{O}$ aerosol composition: Atmospheric implications, Geophys. Res. Lett., 24, 1931-1934.

Taleb, D.-E., J.-L. Ponche, and P. Mirabel (1996), Vapor pressures in the ternary system water-nitric acid-sulfuric acid at low temperature, J. Geophys. Res., 101, 25,967-25,977.

Timmreck, C. (2001), Three-dimensional simulation of stratospheric background aerosol: First results of a multiannual general circulation model simulation, J. Geophys. Res., 106, 28,313-28,332

Tsang, T. H., and J. R. Brock (1983), Simulation of condensation aerosol growth by condensation and evaporation, Aerosol. Sci. Technol., 2, $311-$ 320 .

Turco, R. P., F. Q. Yu, and J. X. Zhao (2000), Tropospheric sulfate aerosol formation via ion-ion recombination, J. Air Waste Manage. Assoc., 50(5), 902-907

Vehkamäki, H., M. Kulmala, I. Napari, K. E. J. Lehtinen, C. Timmreck, M. Noppel, and A. Laaksonen (2002), An improved parameterization for sulfuric acid/water nucleation rates for tropospheric and stratospheric conditions, J. Geophys. Res., 107(D22), 4622, doi:10.1029/ 2002JD002184.

Walton, J. J., M. C. MacCracken, and S. J. Ghan (1988), A global-scale Lagrangian trace speices model of transport, transformation, and removal processes, J. Geophys. Res., 93, 8339-8354.

Weisenstein, D. K., G. K. Yue, M. K. W. Ko, N. Sze, J. M. Rodriguez, and C. J. Scott (1997), A two-dimensional model of sulfur species and aerosols, J. Geophys. Res., 102, 13,019-13,035.

Whitby, E. R., P. H. McMurry, U. Shankar, and F. S. Binkowske (1991), Modal aerosol dynamics modeling, Tech. Rep. 600/3-91/020, Atmos. Res. and Exposure Assess. Lab., U.S. Environ. Prot. Agancy, Research Triangle Park, N. C

Wilson, J., C. Cuvelier, and F. Raes (2001), A modeling study of global mixed aerosol fields, J. Geophys. Res., 106, 34,081-34,108.

Wright, D. L., P. S. Kasibhatla, R. McGraw, and S. E. Schwartz (2001), Description and evaluation of a six-moment aerosol microphysical module for use in atmospheric chemical transport models, J. Geophys. Res., 106, 20,275-20,291.

Yu, S. C., P. S. Kasibhatla, D. L. Wright, S. E. Schwartz, R. McGraw, and A. J. Deng (2003), Moment-based simulation of microphysical properties of sulfate aerosols in the eastern united states: Model description, evaluation, and regional analysis, J. Geophys. Res., 108(D12), 4353, doi:10.1029/2002JD002890.

Zhang, R., I. Suh, J. Zhao, D. Zhang, E. C. Fortner, X. Tie, L. T. Molina, and M. J. Molina (2004), Atmospheric new particle formation enhanced by organic acids, Science, 304, 1487-1490.

Zhang, Y., C. Seigneur, J. H. Seinfeld, M. Z. Jacobson, and F. S. Binkowski (1999), Simulation of aerosol dynamics: A comparative review of algorithms used in air quality models, Aerosol. Sci. Technol., 31, 487-514.

Zhang, Y., B. Pun, K. Vijayaraghavan, S.-Y. Wu, C. Seigneur, S. N. Pandis, M. Z. Jacobson, A. Nenes, and J. H. Seinfeld (2004), Development and application of the model of aerosol dynamics, reaction, ionization, and dissolution (MADRID), J. Geophys. Res., 109, D01202, doi:10.1029/ 2003JD003501

Zhao, J., and R. P. Turco (1995), Nucleation simulations in the wake of a jet aircraft in stratospheric flight, J. Aerosol Sci., 26, 779-795.

M. Herzog and J. E. Penner, Department of Atmospheric, Oceanic, and Space Sciences, University of Michigan, 2455 Hayward Street, Ann Arbor, MI 48109, USA. (herzogm@umich.edu)

D. K. Weisenstein, Atmospheric and Environmental Research, Inc., 131 Hartwell Avenue, Lexington, MA 02421, USA 

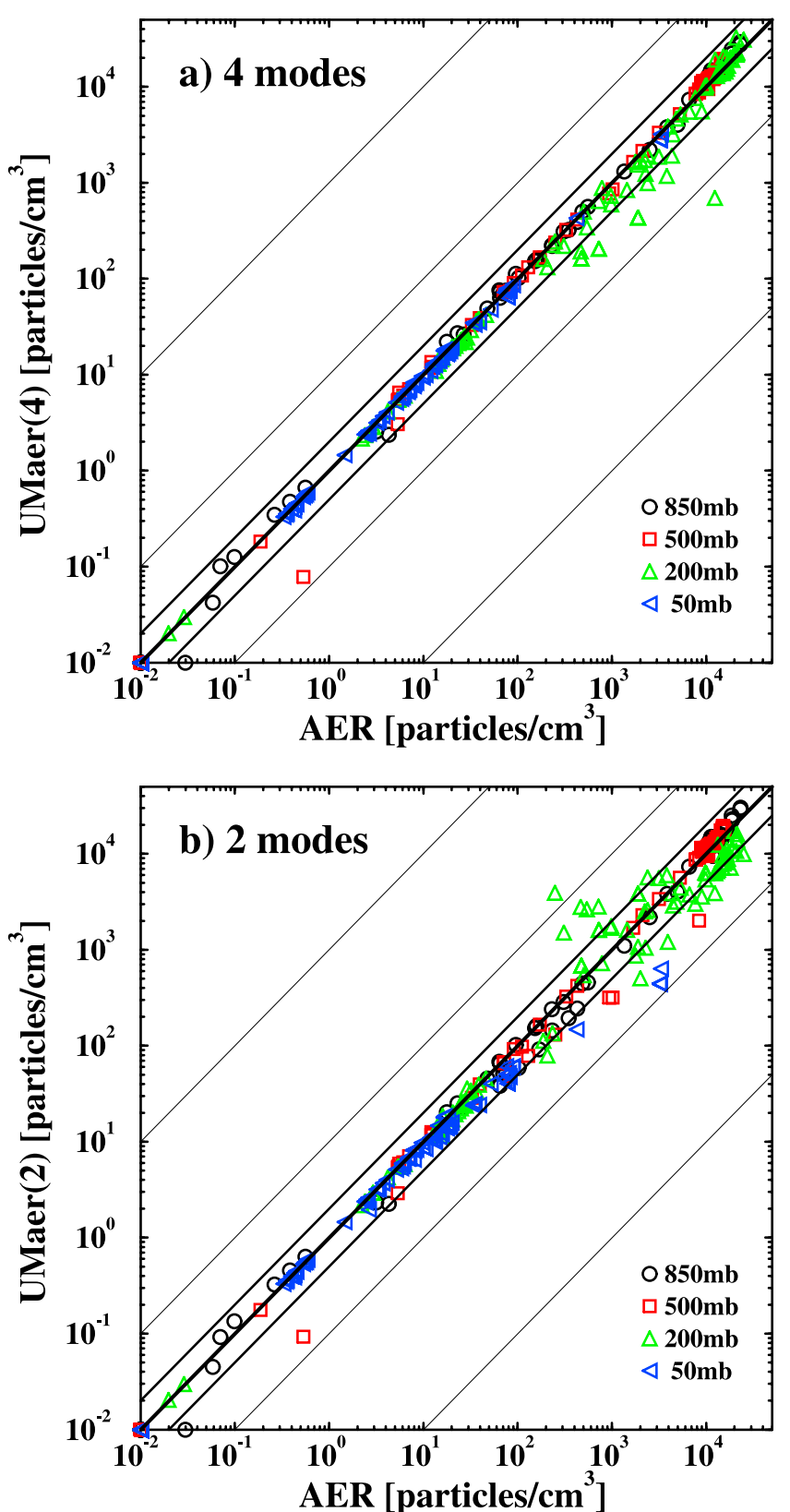

Figure 1. Comparison of total number concentration after 1 day in UMaer and AER for two different configurations of the UMaer model.
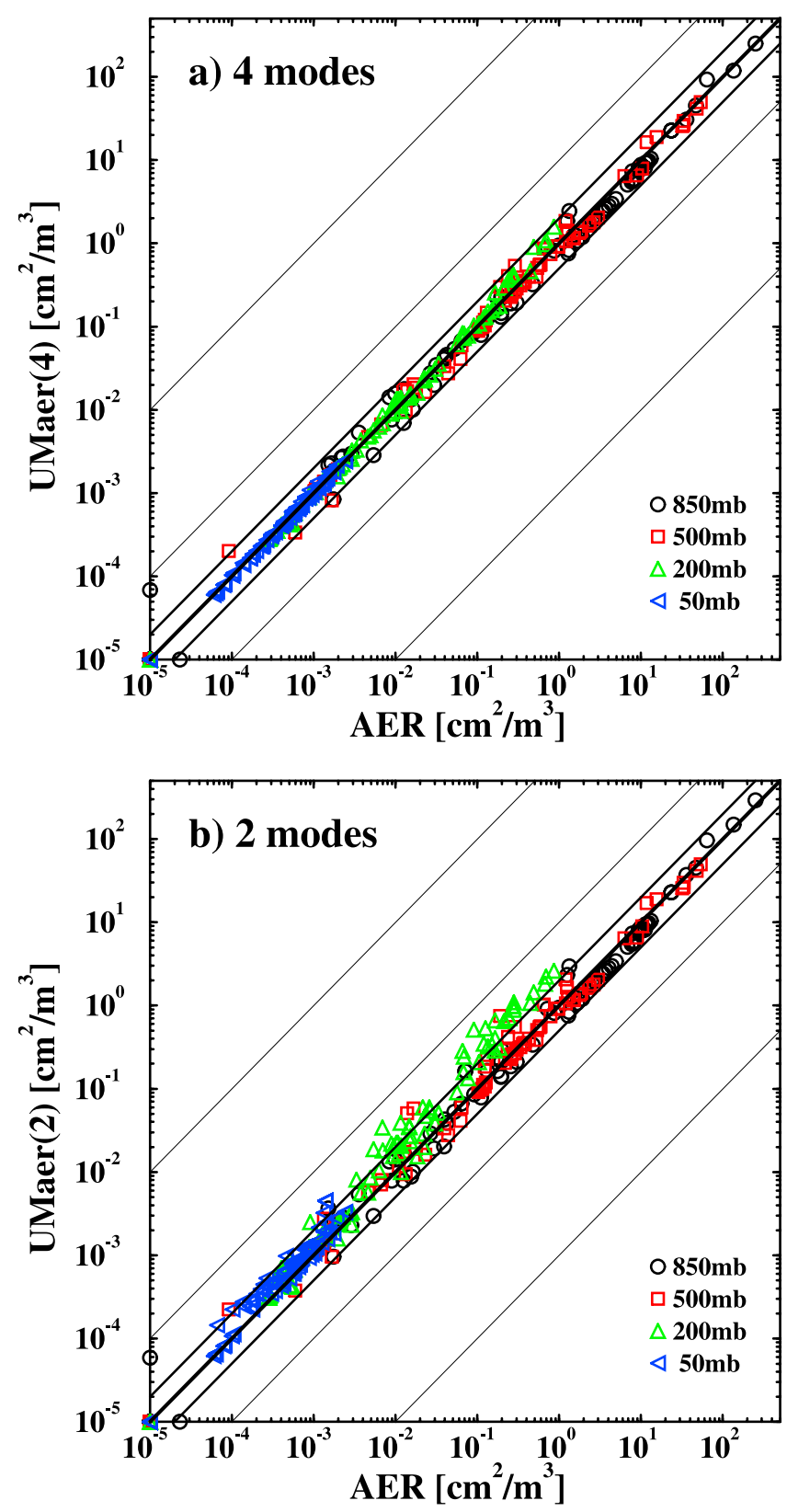

Figure 2. Comparison of surface area concentration after 1 day in UMaer and AER. 

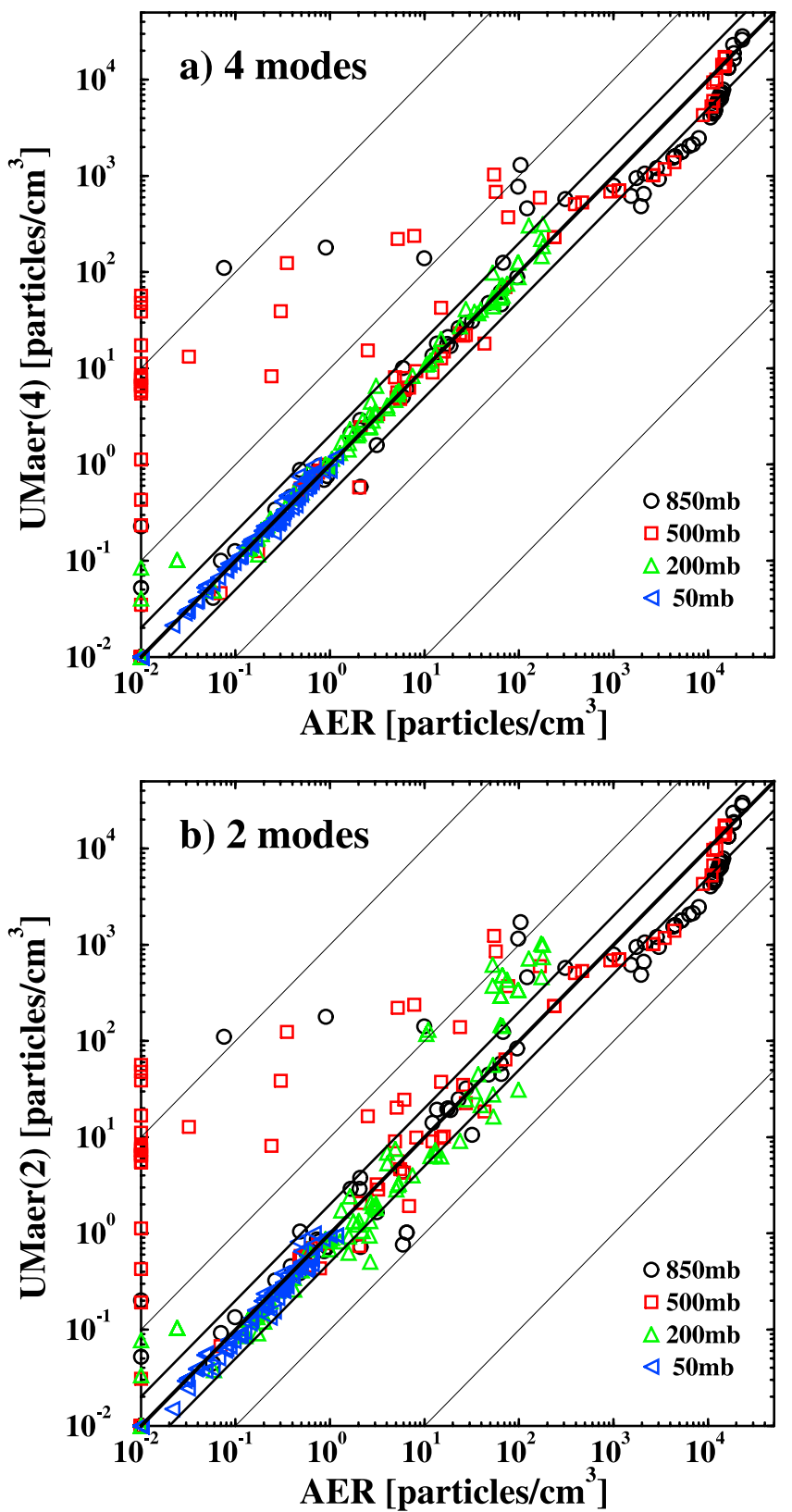

Figure 3. Comparison of accumulation mode particles after 1 day in UMaer and AER.

Figure 5. Effect of the interaction of sulfate with nonsulfate aerosol particles on the pure sulfate aerosol size distribution.
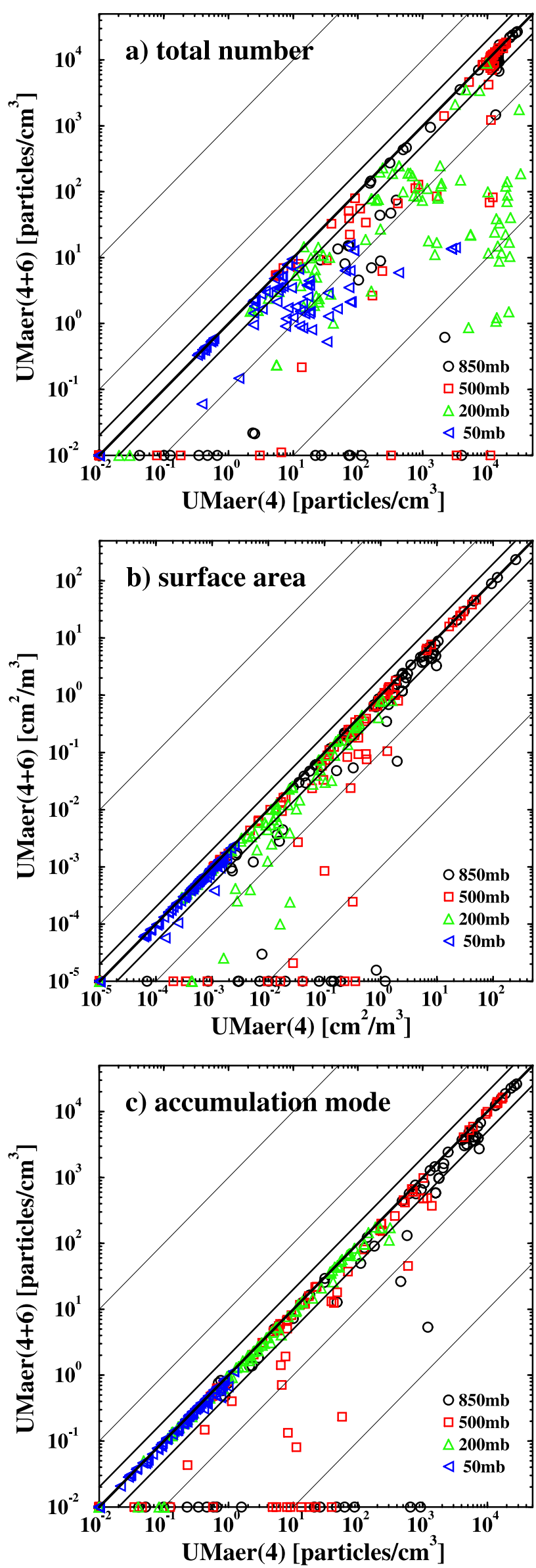